\title{
LA DANZA Y SU VOZ: EXPERIENCIAS EN LA PRÁCTICA COREOGRÁFICA ACTUAL
}

\section{Ixiar Rozas Elizalde}

Mondragon Unibertsitatea (MU)

Azala espazioa

\section{Resumen}

Este ensayo parte de la pregunta que ya hizo Gilles Deleuze -siguiendo la de Spinoza-“¿qué puede un cuerpo?”, con la intención de reformularla de esta manera: ¿Qué puede el entrelazamiento entre la voz, el cuerpo y el lenguaje en el ámbito de la danza? A través de esta cuestión y mediante la investigación de la obra de coreógrafos como Vera Mantero, Idoia Zabaleta, Filipa Francisco e Irena Tomazin, el texto investiga el campo de experiencia y los significados que se abren cuando la danza rompe a hablar.

\section{Palabras clave: VOZ; EXPERIENCIA; COREOGRAFÍA; PERFORMATIVIDAD; BIOPO- LÍTICA}

\section{Abstract}

This essay takes as starting point the question posed by Gilles Deleuze -following Spinoza-, the well known What can a body do?, in order to reformulate it into: What can the interweaving of voice, body, word and language do within dance? Through this question and researching the work by artists such us Vera Mantero, Idoia Zabaleta, Filipa Francisco and Irena Tomazin, the text explores the field of experience, as well as the meanings that arise from a dance that bursts into speaking.

Keywords: VOICE; EXPERIENCE; COREOGRAPHY; PERFORMATIVITY; BIOPOLITICS

\footnotetext{
Fort i Marrugat, oriol. 2015. "Cuando danza y género comparten escenario”. AusArt 3 (1): 66-76. DOI: 10.1387/ausart.14394
}

\section{AUSART}




\section{¿QUIÉN HABLA CUANDO HABLA LA VOZ?}

Es de noche y leo en voz alta: "una voz que habla/ una voz que habla al lado de otra voz que habla/ una voz que habla al lado de otra que habla en el intersticio, en el hueco, en la fisura desprendida de la primera voz, de la segunda voz/ y así dos voces/ dos hablas/que son solo una sola/ voz con la voz del otro que no es sino sí mismo/ voz junto a la voz del otro que no es sino sí mismo (...)"(Bartomeu 2012, 43).

Si una voz habla al lado de otra, y otra al lado de otra junto a otra que no es sino sí mismo, también de noche me pregunto, quién habla entonces cuando habla la voz.

Para tratar de abordar esta última pregunta en este ensayo abriré otra más, partiendo de la que ya hizo Gilles Deleuze retomando a Spinoza (qué puede un cuerpo): ¿Qué puede el entrelazamiento entre la voz, el cuerpo y la palabra en el ámbito de la danza? Se trata de una pregunta que me lleva a explorar el campo de experiencia que se abre en la danza que deja emerger su voz y rompe a hablar. Un campo experiencial en el que analizaré de manera espefícica la experiencia de la voz, del lenguaje y de la tactilidad.

La danza rompe a hablar en los 60 -principalmente con Judson Church-. Sin embargo, la experimentación con la voz y lenguaje se hace más específica en las coreografías de a partir de los 90. La obra de autores como Vera Mantero, Mónica Valenciano, Idoia Zabaleta, Irena Tomazin y Jonathan Burrows permite establecer, precisamente, un diálogo con el campo experiencial que se indaga en esta investigación desde una aproximación genealógica (Burt 2004, 33).

Entonces, ¿por qué los bailarines deciden trabajar con el lenguaje y experimentar con la voz? ¿Por qué la danza emancipa y subvierte su voz a partir de los 90 ? ¿Cuáles son las motivaciones de los artistas que he investigado? ¿Y cuáles son las consecuencias estéticas y éticas de la irrupción de esta voz? 


\section{HABLAR O NO HABLAR. UNA DECISIÓN POLÍTICA}

En una conversación que mantuve con la creadora portuguesa Vera Mantero tras el estreno de su performance We are going to miss everything we don't need en España (Gijón), me explicó que para ella la voz es algo muy liberador. Mantero explica que esta experimentación tiene un sentido político: "Creo que también puede ser muy político no hablar", me explicó Vera. "Lo que siempre me había parecido extraño es que los bailarines fueran algo sin oralidad. Me ha parecido históricamente algo regresivo. (...) Cuando no hablas eres algo diferente, otro animal. Era muy extraña una actividad donde se decidió que no había palabra, lenguaje. Nunca me ha parecido algo normal. En este sentido decidir hablar en una creación coreográfica sí puede ser una decisión política".' Quiero recordar la letanía que Mantero exterioriza en Uma misteriosa coisa, disse e.e. cummings: "Una pena, una imposibilidad, atroces, atroces, una imposibilidad, una pena, atroces, atroces...".

Algunos años antes, me reuní con la creadora Irena Tomazin en Ljubljana. Era una tarde de diciembre. Durante nuestra conversación leí en voz alta un fragmento de su pieza Caprice Relapse (2005): "Necesitas mi voz. Tú necesitas mi voz, porque ya no puedes oír tu propia voz. Ya no puedes escuchar tu voz. Ya no te puedes escuchar más, ya no puedes oír... Prefieres ser oído, incluso preferirías escuchar hasta el final". Tomazin me explicó que llegó a la voz a partir de la danza y la fisicalidad. La noche anterior pude asistir a una de sus performance, era un concierto que compartió con Lidya Lunch. Al igual que Mantero, la performer de Ljubljana tiene también una doble faceta de cantante y en sus trabajos (Caprice Relapse o As a raindrop falling into de mouth of silence), busca en la fisicalidad de la voz. Así, sus creaciones musicales y escénicas se convierten en pura materialidad sonora: "Nunca habría llegado a lugares a los que estoy llegando con la voz si trabajara sólo con el cuerpo" cuenta Irena. "No quiero decir que sea mejor, sino que la voz me está hablando sobre otro cuerpo. Cómo ese cuerpo interno sale al exterior a través de la voz [...]. Es un lugar muy frágil porque la escucha, el sentido de la escucha es algo muy íntimo"2. 


\section{YO ESCUCHO TAMBIÉN QUIERE DECIR ESCÚCHAME}

Este fragmento de Roland Barthes en Lo obvio y lo obtuso dialoga con la afirmación que acaba de hacer Tomazin:

"Oír es un fenómeno fisiológico; escuchar una acción psicológica. [...] El acto de escuchar no puede definirse más que por su objeto o, quizá mejor, por su alcance. [...] Propondremos tres tipos de escucha. De acuerdo con el primer tipo de escucha, el ser vivo orienta su audición hacia los índices. [...] Este primer tipo de escucha es una alerta. La segunda escucha es un desciframiento; lo que se intenta captar por los oídos son signos. Por último, la tecera escucha [...] no se interesa en lo que se dice, o emite, sino en quien habla, en quien emite; se supone que tiene lugar en un espacio intersubjetivo, en el que "yo escucho" también quiere decir "escúchame" (Barthes 2009, 277)

Concluye Barthes en este fragmento que la libertad de escucha es tan necesaria como la libertad de la palabra.

En piezas como As a raindrop falling into the mouth o Caprice Relapse, las voces, los cuerpos y las palabras se convierten en materia, en signo, y como tal pueden ser leídas por nuestra mirada. También escuchadas. Incluso pueden hacerse táctiles si dejamos que la mirada y la escucha caigan en todo nuestro cuerpo. "La voz debe tener una vibración, una bocalidad, una fisicalidad para poder generar una imagen", explica la coreógrafa vasca Idoia Zabaleta, tras la presentación de la pieza Dueto creada junto a Filipa Francisco ${ }^{3}$.

Al explorar estas coreografías me he situado en un territorio de narraciones en el que lo importante, a grandes rasgos, no es lo que se cuenta: pasa a primer plano la materialidad del lenguaje y de las palabras, y la necesidad de introducir los relatos en territorios alejados de la búsqueda de sentido y de la expresividad. En estas piezas escénicas, que también he llamado polifonías coreopoéticas, no buscamos un sentido totalizante.

Hoy no disponemos de grandes metarrelatos sobre el mundo ni sobre la historia. Los relatos se han disuelto en una atomización de narraciones que, en la mayoría de los casos en lugar de situarnos en lo ambiguo, en el cuestiona- 
miento y la problematización, nos enmarcan en un mundo autorreferencial. Un mundo que nos individualiza y nos aísla en la pobreza de experiencia que puebla nuestra cotidianeidad ${ }^{4}$.

En estas polifonías la voz se trabaja como un material escénico más. Se separa del cuerpo y del lenguaje compuesto. Y en su materialidad, la voz pasa a ser una de las condiciones de la experiencia de la tactilidad. La voz pasa a ser un mísil corporal que escapa, habita el espacio entre el yo y el tú, entre el yo y el otro, para regresar al cuerpo.

La voz habita entre el cuerpo y el lenguaje, media entre el cuerpo y el lenguaje $y$, sin embargo, no pertenece a ninguno de los dos. Como si al hablar nuestra voz no nos perteneciera. Como si habláramos con voces que emergen a la vez de varios cuerpos o lugares. También el yo se descompone: en esa voz que es nuestra y no nos pertenece del todo, en ese lenguaje y esos cuerpos llenos de fisuras, el yo pasa a ocupar un lugar desubjetivado. En la descomposición de todos los elementos escénicos se genera entonces un espacio de interrupciones, trazos, remanentes, huellas: la danza como un acto que no finaliza en sí mismo: un acto de potencia, si entendemos la potencialidad como un acto no culminado del todo, siempre en curso, como constelación temporal.

La voz tiene algo que excede al lenguaje. Sobrepasa y escapa al significado literal y los significados establecidos. Y cuando la danza decide irrumpir con la experimentación de sus voces, se rompe también la estabilidad de la danza: una ruptura que implica, al mismo tiempo, una potencia de apertura. Pero, ¿quién habla cuando habla la voz?

\section{LA VOZ ES ENTRE DOS}

Escribe el filósofo esloveno Mladen Dólar que la voz se sitúa en un lugar de ambivalencia y fragilidad, entre interior y exterior. Lo cierto es que resulta difícil establecer una distancia para poder dibujar una línea divisoria entre el mundo exterior y el interior. No en vano, la voz es pura alteridad. La voz no pertenece ni al emisor ni al receptor, tampoco al sujeto ni al otro, al igual que no pertenece al cuerpo ni al lenguaje: "La voz está entre dos, situada precisamente en una curiosa intersección”, escribe Dólar $(2006,103)$. 
A partir de aquí, Dolar explora la dimensión política de la voz. Para entenderla es preciso distinguir la diferencia que existe entre la mera voz (phone) y la palabra inteligible (logos). La mera voz es lo que los animales y los seres humanos tienen en común: puede indicar solamente placer y dolor, experiencia que comparten tanto animales como humanos. Para Dolar el discurso no sólo indica, sino que es expresión de algo, es más bien una manifestación. En el fondo de esta diferencia se encuentra la oposición entre dos formas de vida: zoe y bios. Zoe es la vida desnuda, la pura vida reducida a la animalidad y bios la vida en la comunidad, la vida política. El filósofo esloveno recurre a la explicación de nuda vita que Agamben ofrece en Homo Sacer. Agamben hace una analogía entre phone, perteneciente al zoe, y logos perteneciente al bios. La voz es como la nuda vida, algo que es supuestamente exterior a lo político, mientras que el logos es lo equivalente a la polis, a la vida social regulada por las leyes y el bien común. La tesis de Agamben en este libro es que no existe una simple exterioridad. La estructura básica, la topología de lo político es para Agamben "la exclusión inclusiva de la nuda vida". Esto, continúa Dolar, sitúa a la voz en un lugar aún más paradójico y peculiar en, "la topología de la extimidad $(2006,106-7)$ (extimacy), una simultánea inclusión/ exclusión, que retiene lo excluido en su núcleo. La voz se convierte, entonces, en algo fundamental y ambivalente. El pasaje de la voz al logos es un pasaje inmediatamente político, conlleva la reemergencia de la voz en medio de lo político. En su ser precario y escurridizo, en esa extimidad (extimacy) que es a la vez exclusión e inclusión, encontramos precisamente la potencia de apertura y la capacidad de desestabilización de la voz que también afecta a la coreografía que está experimentando con sus voces.

\section{OTRAS FORMAS DE ENTENDER LA COMUNICACIÓN Y EL CUERPO}

Entonces, retomando la pregunta que hacíamos al inicio, ¿qué puede el encuentro entre la voz, el cuerpo y el lenguaje en la coreografía experimental? Estas prácticas artísticas hacen visibles otras formas de comunicación y otras maneras de entender el cuerpo. Como es sabido, una de las demandas de la vida social y política es la necesidad de tener una voz. Una voz que se escuche, una voz que tenga consecuencias, que incida en las decisiones que afectan nuestras vidas. Una voz que no se limite a ser convocada cada cua- 
tro años. Sin embargo, como sabemos, esta demanda se diluye en nuestra cotidianeidad y cae en el automatismo. De hecho, nuestras voces terminan conformándose con ser convocadas cada cuatro años y también aceptan el espectáculo de la representación política. Frente a una expropiación de nuestras posibilidades de comunicación, en una sociedad en la que el lenguaje mismo se ha convertido en espectáculo, urge que nos cuestionemos sobre nuestra propia potencia de lenguaje. $\mathrm{O}$ en otras palabras, urge que miremos y pensemos qué significa hoy hacer una experiencia de lenguaje.

Escribe Agamben que el problema de la pobreza de experiencia debe toparse con el problema del lenguaje. Según Agamben, el problema del lenguaje se hace visible en la infancia: cuando pasamos de la mera emisión de sonidos al habla, de la voz, al habla. Sin embargo, esta experiencia de toma de palabra no puede situarse solamente en la infancia, Agamben no habla de infancia en sentido cronológico. Al contrario: hacemos experiencia de lenguaje cada vez que damos el paso de la lengua al discurso, cada vez que nos faltan las palabras o éstas se interrumpen en nuestros labios. Y esto es algo que nos sucede durante toda la vida (Agamben 1978, 70).

Precisamente, en las creaciones que he cartografiado también vivenciamos la experiencia de lenguaje a la que se refiere Agamben: son prácticas que demandan su propio lenguaje (lo hacen balbucear, lo implosionan) y también su propia voz (la subvierten, la emancipan). Y con esta toma de posición, están haciendo visibles otras formas de comunicación. Otras formas de comunicación que pasan por la deconstrucción de la voz -la separan del significado, el campo de lo semántico para trabajar su materialidad-, el cuerpo y el lenguaje, mecanismos que rompen y desplazan el logocentrismo y la discursivización.

Con Derrida entendemos por logocentrismo una orientación de la filosofía que tiende hacia un orden del significado. Es decir, hacia la Verdad, la Razón, la Lógica, el Mundo, el Pensamiento, todas en mayúsculas. Se impone la autoridad del logos, del significado trascendental y, seguimos a Derrida, se justifica el orden masculino. Desmontar el logocentrismo significa entonces, desplazar la autoridad del logos; desplazar la palabra como privilegio del habla, desmontar también la autoridad del orden masculino.

Si nos situamos ahora en el punto de vista de la filosofía del lenguaje, también la performatividad está relacionada con estos desplazamientos. Podemos entender la performatividad, y cito a Derrida, como "comunicar una fuerza por el impulso de una marca" (De Peretti 1989, 34). La performatividad produce o 
transforma una situación: no se limita a transportar un contenido semántico, no hay intención de verdad. Para Paolo Virno, cada acto de habla es una acción y la voz es el enunciado performativo del "yo hablo". Precisamente, el yo hablo es para el pensador italiano, el performativo absoluto, un espacio potencial (Virno 2003, 17).

Estas prácticas también están haciendo visibles otras maneras de entender el cuerpo. Un cuerpo que trabaja con la vibración y la resonancia de la voz es un cuerpo afectado, denso, opaco. También un cuerpo atravesado por intensidades y flujos de deseo que circulan entre la interioridad y la exterioridad. Un cuerpo que alberga muchos cuerpos. Una vez que alguien se adentra en las potencialidades de su propio cuerpo, entendido como posibilidad de afectar y ser afectado, se inicia un proceso, siempre en devenir, que choca con la idea de un sujeto fijo. El cuerpo que entra en acción puede activar procesos de subjetivación que se alejan de una identidad cerrada y lo hace con los otros: la producción de modos de subjetivación singulares también puede dar lugar a la intersubjetividad (Guattari y Rolnik 2006).

Es conocida la tesis de Rancière en "The emancipated spectator". Rancière aboga por la creación de un tercer camino, un camino que invalida la oposición entre actividad y pasividad. A diferencia de la propuesta de Ranciére, aquí no estamos proponiendo un tercer camino que se sitúe entre la actividad y la pasividad. La "emancipación" pasa en este trabajo por un nivel de percepción, sensación y afectos. Más que por una emancipación pasa por una implicación cognitiva y sensorial, por activar una mirada y una escucha que caen en todo nuestro cuerpo: una mirada y una escucha que he llamado táctiles porque todos los sentidos pueden ser una especie de tacto.

Este cuerpo, estas voces y estos lenguajes no sólo revelan otra corporalidad (es decir, una postura emancipatoria hacia el cuerpo y la subjetividad), sino también otra audibilidad. Pero en la pobreza de experiencia de un lenguaje que hoy se ha convertido en espectáculo, se hace preciso mirar más allá de esta audibilidad 5 .

La audibilidad del cuerpo, la voz y el lenguaje que actúa en la redistribución de tiempos y espacios, condiciones de nuestra sensibilidad, mueve continuamente el campo gravitacional de los afectos, la posibilidad de un empoderamiento afectivo. Sin embargo, además de expropiar nuestra capacidad de lenguaje, el capitalismo ya ha corporativizado la producción afectiva ${ }^{6}$. Así que tampoco me estoy refiriendo a una estética relacional, sino a prácticas 
artísticas que hacen visibles maneras de subvertir un cuerpo inmunizado y homeopático. ¿A qué me refiero con esta última afirmación?

El afecto es la capacidad de hacer. Su vitalidad o potencial interactúa con otro cuerpo. Lo importante no es lo que se expresa en un afecto, sino lo que se mueve, se renueva y diferencia. El campo gravitacional afectivo pasa en nuestro caso por la voz, por la intimidad y la exterioridad que conforma la voz. O como diría Agamben, por la extimidad que representa la voz. Esta extimidad está relacionada con la tercera persona, con un lugar impersonal y una ruptura de la identidad fija. Un lugar impersonal, de tercera persona, en la que el filósofo italiano Roberto Esposito sitúa la animalidad. El animal, el devenir animal, que Esposito actualiza a partir de Deleuze, significa sobre todo multiplicidad, pluralidad y encadenamiento. Se difumina la frontera entre identidades para crear un umbral vibratorio entre cuerpos que están en proximidad. Se trata de un humano- animal y de un animal- humano, dos caras de la misma fractura, donde se obtiene una nuda vida (Esposito 2007, 3).

Como es sabido el orden biopolítico se produce cuando la vida misma, su protección, se convierte en la base de la política. El cuerpo es el campo de batalla entre la política y la vida. Obviamente las prácticas artísticas que he cartografiado no escapan del paradigma biopolítico. Sin embargo, en estas coreografías el cuerpo inmunizado y protegido se suspende, se subvierte. Nuestros cuerpos de receptores y creadores implicados, no inmunizados, no homeopáticos, se entrelazan, se contaminan: pueden abrirse fisuras que no se limitan al presente escénico.

Estas prácticas artísticas performativas, cuya fuerza no reside tanto en el hablante sino en la repetición, sedimentación y diseminación de sus actos, mantienen un diálogo extradisciplinar con cuestionamientos del pensamiento y la política contemporáneos. Este cuerpo lingüístico y vocal se abre a otras formas de comunicación y de transformación del cuerpo. El cuerpo de la demanda otra comunicación, demanda su propia voz, quiere hacerse ruidoso, gravitacional, pesado. Un cuerpo que demanda su voz en un nivel artístico pero que es reflejo de una demanda extensible a lo social.

La voz continúa leyendo de noche. Voz entre la voz del otro. Voz entre la voz de la otra. 


\section{Referencias}

Agamben, Giorgio. 1978. Infanzia e historia. Torino: Einaudi

— 2007. Infancia e historia. Buenos Aires: Adriana Hidalgo

Barthes, Roland. 2009. Lo obvio y lo obtuso: Imágenes, gestos y voces. Barcelona: Paidos

Burt Ramsay. 2004. "Genealogy and dance history" P. 33 en Of the presence of the body. Andre Lepecki, ed. London: Routledge

Cavarero, Adriana. 2003. A piu voci: Filosofia della espresione vocale. Torino: Einaudi

De Peretti, Cristina. 1989. Jaques Derrida: Texto y deconstrucción. Barcelona: Anthropos

Dolar, Mladen. 2006. A voice and nothing more. Cambridge MA: MIT

Esposito, Roberto. 2007. Terza persona: Politica della vita e filosofia dell'impersonale, Torino: Einaudi

Ferrando Colom, Bartomeu. 2012. Arte y cotidianeidad: Hacia la transformación de la vida en arte. Madrid: Ardora

Guattari, Félix y Suely Rolnik. 2006. Micropolítica: Cartografías del deseo. Madrid: Traficantes de Sueños

Kunst, Bojana. 2009. "The voice of the dancing body". Performing Arts Journal 51/52 (Autumn): 144-60

Lehmann, Hans-Thies. 2006. Postdramatic Theatre. London: Routledge

Lepecki, Andre. 2006. Exhausting Dance. New York: Routledge

Pallasmaa, Juhani. 2006. Los ojos de la piel: La arquitectura y los sentidos, Barcelona: Gustavo Gili

Rozas Elizalde, Ixiar. 2012. Voic(e)scapes: Experiencias y potencias de la voz, el lenguaje y la tactilidad en la escena actual de la danza. Tesis doctoral, Universidad del País Vasco/Euskal Herriko Unibertsitatea. CD-ROM

Virno, Paolo. 2003. Quando il verbo si fa carne: Linguaggio e natura umana. Milano: Bollati Boringhieri

Zournazi, Mary 2009. "Briam Massumi in conversation with Mary Zournazi”. En The Swedish Dance History: A collective choreography of 1000 pages organised by INPEX and MyChoreography.org in Stockholm on the 29th of April 2009 during the International Day of Dance. Stockholm: Inpex-MyChoreography.org

- 2015. "Briam Massumi in conversation with Mary Zournazi". En Ejercicios de ocupación: Afectos, vida y trabajo. Quim Pujol e Ixiar Rozas, eds. Cuerpo de Letra \# 5, Danza y Pensamiento. Barcelona: Polígrafa

\section{Notas}

${ }^{1}$ Fragmento de la conversación mantenida con Vera Mantero en Gijón, 9/5/2010

${ }^{2}$ Fragmento de la conversación mantenida con Irena Tomazin en Ljubljana (Eslovenia) en diciembre de 2009 
${ }^{3}$ Fragmento de las dos conversaciones mantenida con Idoia Zabaleta y Filipa Francisco en Azala (Lasierra, 18/12/2008) y en Vigo (13/03/2009).

${ }^{4} \mathrm{Hago}$ aquí referencia a lo que escribe Agamben al retomar la pobreza de experiencia que ya vaticinó Benjamin cuando los soldados regresaban mudos del campo de batalla durante la Primera Guerra Mundial (Agamben 1978).

5 Tomo la idea de la audibilidad del artículo "The voice of the dancing body" (Kunst 2009: 14460)

6 "Briam Massumi in conversation with Mary Zournazi" en The Swedish Dance History (Stockholm: Inpex-MyCoreography.org, 2009). Publicada en castellano en Ejercicios de ocupación: Afectos, vida y trabajo (Barcelona: Polígrafa, 2015) 